\title{
Molecular Mechanisms of Glucose Fluctuations on Diabetic Complications
}

\author{
Zhen-Ye Zhang ${ }^{\dagger}$, Ling-Feng Miao ${ }^{\dagger}$, Ling-Ling Qian, Ning Wang, Miao-Miao Qi, \\ Yu-Min Zhang, Shi-Peng Dang, Ying Wu and Ru-Xing Wang* \\ Department of Cardiology, Wuxi People's Hospital Affiliated to Nanjing Medical University, Wuxi, China
}

\section{OPEN ACCESS}

Edited by:

Anca Dana Dobrian

Eastern Virginia Medical School,

United States

Reviewed by:

Helena Barbosa Sampaio,

Campinas State University, Brazil

Krzysztof W. Nowak,

Poznan University of Life

Sciences, Poland

*Correspondence:

Ru-Xing Wang

ruxingw@aliyun.com

tThese authors have contributed equally to this work

Specialty section:

This article was submitted to

Clinical Diabetes,

a section of the journal

Frontiers in Endocrinology

Received: 06 October 2018 Accepted: 03 September 2019

Published: 18 September 2019

Citation:

Zhang Z-Y, Miao L-F, Qian L-L,

Wang N, Qi M-M, Zhang $Y-M$,

Dang S-P, Wu Y and Wang R-X (2019)

Molecular Mechanisms of Glucose

Fluctuations on Diabetic

Complications.

Front. Endocrinol. 10:640.

doi: 10.3389/fendo.2019.00640
Accumulating evidence indicates the occurrence and development of diabetic complications relates to not only constant high plasma glucose, but also glucose fluctuations which affect various kinds of molecular mechanisms in various target cells and tissues. In this review, we detail reactive oxygen species and their potentially damaging effects upon glucose fluctuations and resultant downstream regulation of protein signaling pathways, including protein kinase $\mathrm{C}$, protein kinase $\mathrm{B}$, nuclear factor$\kappa \mathrm{B}$, and the mitogen-activated protein kinase signaling pathway. A deeper understanding of glucose-fluctuation-related molecular mechanisms in the development of diabetic complications may enable more potential target therapies in future.

Keywords: glucose fluctuations, diabetes, reactive oxygen species, protein kinase C, protein kinase B, mitogenactivated protein kinase

\section{INTRODUCTION}

Diabetes is a chronic metabolic disorder and a threat to human health in the world (1). In the past decades, it has been verified in both clinical and experimental studies that glucose fluctuations are more harmful than in a comparative state of constant hyperglycemia (2). Recently, increasing levels of experimental researches have investigated the relationship between glucose fluctuations and diabetic complications (3). This review is focused on describing the variety of underlying molecular mechanisms influencing glucose fluctuations on diabetic complications in different tissues and organs.

\section{OVERVIEW AND DIAGNOSTIC INDICATORS OF GLUCOSE FLUCTUATIONS}

With the development of new technologies such as continuous blood glucose monitoring systems, measurements of blood glucose fluctuations have become increasingly accurate, providing new research directions for clinical and basic studies (4). The standard deviation of the mean around the mean glucose value is a golden standard to measure glucose variability (5). However, the mean amplitude of glycemic excursions index is more advanced and also appropriate (6). Commonly used indicators include (Table 1): (1) mean amplitude of glycemic excursions (7); (2) standard deviation of the mean (8); (3) coefficient of variation (9); (4) glycemic lability index (10); (5) mean of daily difference (11); (6) continuous overlapping net glycemic action (12); (7) high blood glucose index and low blood glucose index (12). 
TABLE 1 | Commonly used indicators for blood glucose fluctuations.

\begin{tabular}{|c|c|c|}
\hline Concept & Definition/Calculation & Advantage \\
\hline $\begin{array}{l}\text { Mean amplitude of glycemic excursions } \\
\text { (MAGE) }\end{array}$ & $\begin{array}{l}\text { The mean of blood glucose values exceeding } \\
\text { one SD from the } 24-\mathrm{h} \text { mean blood glucose. }\end{array}$ & $\begin{array}{l}\text { The most commonly used term as an indicator of } \\
\text { blood glucose fluctuations. }\end{array}$ \\
\hline Standard deviation of the mean(SD) & $\begin{array}{l}\text { Standard deviation of patient's mean blood } \\
\text { glucose level in a certain period of time. }\end{array}$ & $\begin{array}{l}\text { It represents the change and dispersion rate of the } \\
\text { average blood glucose concentrations. }\end{array}$ \\
\hline Coefficient of variation(CV) & $\mathrm{SD} /$ mean $\times 100 \%$ & $\begin{array}{l}\text { It normalizes glycemic variability at different mean } \\
\text { blood glucose values. }\end{array}$ \\
\hline Glycemic lability index(LI) & $\begin{array}{l}\text { It processes three glucose values to calculate a } \\
\text { lability value and then moves to the next three } \\
\text { glucose values, and so on. }\end{array}$ & It can serve as an indicator of patients' prognosis. \\
\hline Mean of daily difference (MODD) & $\begin{array}{l}\text { It is calculated as the average of the difference } \\
\text { between values on different days but at the } \\
\text { same time. }\end{array}$ & $\begin{array}{l}\text { It can be used to assess the continuous changes of } \\
\text { blood glucose between different days. }\end{array}$ \\
\hline $\begin{array}{l}\text { Continuous overlapping net glycemic } \\
\text { action (CONGA) }\end{array}$ & $\begin{array}{l}\text { It is calculated by determining the difference } \\
\text { between values at different set intervals, and } \\
\text { the difference is then applied to the CONGA } \\
\text { formula. }\end{array}$ & $\begin{array}{l}\text { It is a parameter that reflects the variability of blood } \\
\text { glucose over a certain time interval. }\end{array}$ \\
\hline $\begin{array}{l}\text { High blood glucose index (HBGl) and low } \\
\text { blood glucose index (LBGI) }\end{array}$ & $\begin{array}{l}\text { They are implemented by converting glucose } \\
\text { values into risk scores. If the glucose risk score } \\
\text { is below } 0 \text {, then the risk is labeled as LBGI, and } \\
\text { if it is above } 0 \text {, then it is labeled as HBGI. }\end{array}$ & $\begin{array}{l}\text { They can assess the risk of severe hypoglycemia or } \\
\text { hyperglycemia in diabetic patients. }\end{array}$ \\
\hline
\end{tabular}

See text for references.

\section{RELATIONSHIP BETWEEN GLUCOSE FLUCTUATIONS AND DIABETIC COMPLICATIONS}

\section{Glucose Fluctuations and Microvascular Complications}

Glucose fluctuations can lead to chronic kidney disease characterized by progressive albuminuria eventually leading to end-stage renal failure in type 2 diabetes (13). Several clinical studies conducted in patients with type 2 diabetes have indicated that glucose fluctuations may induce a decrease in glomerular filtration rate and increase the risk of chronic kidney disease (14). In addition, it has been observed in animal-based research and modeling of mice and rats with both two types of diabetes that glucose fluctuations can alter renal tissue structure, promote renal fibrosis, and thicken capillary basal membrane $(15,16)$.

Diabetic retinopathy (DR) is a microvascular complication, which is considered as one of the main causes of visual impairment and blindness (17). DR-related glucose fluctuations can lead to the gradual onset of neurodegeneration and structural damage of the retina, ultimately causing blindness in patients with type 1 diabetes (18). However, whether or not fasting plasma glucose variability is a risk factor that can be used to predict the

Abbreviations: AKT, Protein kinase B; DR, Diabetic retinopathy; ERK1/2, Phosphorylation of MAPK; GA, Glycoalbumin; GPx, Glutathione peroxidase;

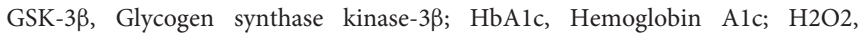
Hydrogen peroxide; MAPK, Mitogen-activated protein kinase; MiRNAs, MicroRNAs; NADPH, Nicotinamide adenine dinucleotide phosphate; NOS, Nitric oxide synthases; $\bullet \mathrm{O}_{2}^{-}$, Superoxide; $\bullet \mathrm{OH}$, Hydroxyl radical; PKC, Protein kinase C; PQS, Panax quinquefolius saponi; PTEN, Phosphatase and tensin; ROS, Reactive oxygen species; SOD, Superoxide dismutase; Trx, Thioredoxin; Txnip, Trx interacting protein; UCP2, Uncoupling protein 2; VEGF, Vascular endothelial growth factor; $\beta$-cells, Pancreatic islet Beta cells. occurrence of DR is controversial (19). It is commonly accepted that intensive glycemic control can reduce the incidence and damage of DR (20).

Glucose fluctuation is an important risk factor in the morbidity of diabetic neuropathy, including peripheral and autonomic neuropathy (21). Several retrospective longitudinal studies conducted on patients with type 1 diabetes found that glucose fluctuations might be a contributing factor in development of diabetic peripheral neuropathy (22), as well as cardiovascular autonomic neuropathy (23). Diabetic neuropathy can cause impairment of cardiac autonomic modulation, which can be alleviated by controlling undesirable glucose fluctuations, especially in women with type 2 diabetes (24). However, Siegelaar et al. (25) contrastingly found that glucose fluctuation was not involved in the development of autonomic and peripheral neuropathy in patients with type 1 diabetes. Therefore, the relationship between glucose fluctuations and neuropathy in diabetic patients still needs further study.

\section{Glucose Fluctuations and Macrovascular Complications}

In addition to microvascular complications discussed above, glucose fluctuations can also have detrimental effects on vessels, leading to cardiovascular, cerebrovascular, and peripheral vascular diseases. Many cardiovascular complications are associated with glucose fluctuations, including heart failure (26), and arrhythmia (27). The relationship between coronary heart disease and glucose fluctuations is antagonistic such that the latter can gradually cause coronary plaque accumulation (28). Further, patients with type 2 diabetes and coronary heart disease have larger glucose variability than those without coronary heart disease (29). Additionally, more serious glucose fluctuations may lead to higher risk of cerebral infarction in patients with 
type 2 diabetes, accompanying with worse prognosis (30). Moreover, cardiovascular events may increase in patients with acute ischemic stroke and glucose fluctuations (31).

\section{Glucose Fluctuations and Cognitive Impairment}

In addition to the vascular complications, the relationship between glucose fluctuations, and cognitive dysfunction in diabetics also should not be ignored. Kinoshita et al. (32) evaluated glycoalbumin (GA)/hemoglobin A1c (HbA1c) ratio, Hasegawa dementia scale-revised score and mini mental state examination score of elderly type 2 diabetics and found that $\mathrm{GA} / \mathrm{HbA} 1 \mathrm{c}$ ratio independently determined the degree of cognitive impairment. Clinical research of Cui et al. (33) have found that gray matter atrophy induced by glucose fluctuations might be responsible for cognitive decline.

\section{POSSIBLE MECHANISMS MEDIATED BY GLUCOSE FLUCTUATIONS}

\section{ROS Involved in the Regulation of Diabetic Complications}

Reactive oxygen species (ROS), as byproducts containing oxygen, are generated through multiple cellular, and physiological mechanisms. ROS contain free radicals including superoxide $\left(\bullet \mathrm{O}_{2}^{-}\right)$, hydroxyl radical $(\bullet \mathrm{OH})$, and hydrogen peroxide $\left(\mathrm{H}_{2} \mathrm{O}_{2}\right)$ (34). Nicotinamide adenine dinucleotide phosphate (NADPH) oxidases, mitochondrial sources and uncoupled nitric oxide synthases (NOS), lipoxygenase, cyclooxygenase, and xanthine oxidase are the major sources of ROS production (1). Excessive generation of ROS plays a significant role in various kinds of physiological and pathological processes (1). Effects of ROS overproduction include the oxidation of DNA, lipid membranes, and proteins (35). Moreover, ROS may also activate oxidative stress-related downstream pathways and lead to indirect cellular damage (36).

\section{The Increase of ROS Induced by Glucose Fluctuations}

There are relatively few clinical studies that have examined whether glucose fluctuations can cause increased ROS production in diabetic patients. Hoeldtke et al. (37) proposed that excessive oxidative stress correlated with insulin requirements and may lead to $\beta$-cell damage in early-staged type 1 diabetic patients. Urinary excretion rate of free 8 -iso prostaglandin F $2 \alpha$ is an indicator for lipid peroxidation and apparently also may be increased in type 2 diabetic patients with blood glucose fluctuations (38). Compared with chronic sustained hyperglycemia, acute glucose fluctuations seem to be a triggering effect more specifically linked to increased ROS levels (39). Ohara et al. (40) demonstrated that improvements in glycemic variability may reduce oxidative stress in patients with type 2 diabetes. However, a clinical study conducted by Wentholt et al. (41) showed no relationship between ROS and glucose fluctuations in a cohort of type 1 diabetic patients. Correspondingly, more clinical studies are needed to explore the potential relationship between ROS and glucose fluctuations for both type 1 and type 2 diabetic patients.

\section{Impact of Glucose Fluctuations on the Antioxidant Defense System}

The generation of ROS and scavenging effect of the antioxidant defense system jointly maintain body homeostasis. The antioxidant defense system exerts a restorative function through reversing protein oxidation and damage. The major endogenous antioxidants include superoxide dismutase (SOD), catalase, glutathione peroxidase (GPx), thioredoxin (Trx), vitamin E, and Coenzyme Q10 (42).

The excessive harmful $\mathrm{H}_{2} \mathrm{O}_{2}$ and $\bullet \mathrm{OH}$ are rapidly removed via various antioxidant systems. SOD converts $\bullet \mathrm{O}_{2}^{-}$to $\mathrm{O}_{2}$ and $\mathrm{H}_{2} \mathrm{O}_{2}$. Catalase converts $\mathrm{H}_{2} \mathrm{O}_{2}$ to oxygen and $\mathrm{H}_{2} \mathrm{O}$. GPx converts hydroperoxides to $\mathrm{H}_{2} \mathrm{O}$ and alcohols (42). The $\bullet \mathrm{O}_{2}^{-}$is released from NADPH oxidase, the mitochondrial respiratory chain and eNOS uncoupling, thus, SOD plays a critical role in maintaining oxidative balance (43). Hyperglycemia reduces SOD levels and impairs heart (44), renal (45), and brain (46). Moreover, SOD levels have been reported to be reduced to a greater extent in glucose fluctuations than persistent hyperglycemia $(16,47)$. GPx1 is expressed most abundantly among GPx isoforms and involved in the detoxification of $\mathrm{H}_{2} \mathrm{O}_{2}$ (48). GPx1 levels are decreased in diabetic rats and the deficiency of GPx1 accelerates atherosclerosis by enhancing pro-inflammatory and pro-fibrotic mechanisms in cardiovascular system (49). Both GPx and catalase levels are reduced in diabetes (50). However, the changes of GPx and catalase levels in diabetes with glucose fluctuations are still unclear.

The Trx system helps to prevent oxidative damage through peroxiredoxins on the setting of physiological conditions (51). Trx seems to function as a protective factor under high glucose conditions (52). Persistent hyperglycemia impairs Trx activity in various target organs, including heart (53), renal (54), and brain (55). However, few data are found in the relationship between glucose fluctuations and Trx. Trx interacting protein (Txnip), a cytosolic protein, binds thioredoxin, and inhibites thioredoxin function. Txnip expression has been reported to be apparently higher in glucose fluctuation group than that in uncontrolled diabetic group (27). The overexpression of Txnip is thought to play an important role in apoptosis of cardiomyocytes and helps to negatively regulate cardiac hypertrophy. Fang et al. (56) found that Txnip overexpression was induced by hyperglycemia through ROS/MEK/MAPK signaling pathway. Along with the increased the processes related to the ROS levels, upregulation of Txnip may be a potential mechanism underlying cardiac apoptosis, and fibrosis in response to glucose fluctuations.

Vitamin $\mathrm{E}$ is a lipid-soluble antioxidant and vitamin $\mathrm{C}$ is a water-soluble antioxidant. Vitamin E helps to protect the cell by inhibiting lipid peroxidation (57). Vitamin $\mathrm{C}$ reacts with $\bullet \mathrm{O}_{2}^{-}$ and $\bullet \mathrm{OH}$ to form the dehydroascorbic acid (58). Hyperglycemia leads to the reduction of vitamin $\mathrm{E}$ and vitamin $\mathrm{C}$ even their dietary intake is normal (59). Coenzyme Q10 functions as an electron transfer intermediate to add two protons and two electrons to ubiquinone in respiratory chain, which prevents lipid peroxidation. Coenzyme Q10 levels have been reported 
to be reduced in diabetes (60). However, the effects of glucose fluctuations on vitamin E, vitamin C and coenzyme Q10 levels need further researches.

\section{Damages From ROS Overproduction}

Diabetes has been reported to be linked to an increase in ROS generation and/or a reduction in antioxidant defenses. Hyperglycemia leads to the ROS overproduction through mitochondrial respiratory chain enzymes, NOS, xanthine oxidases, lipoxygenases, and peroxidases (1). The metabolic route of diacylglycerol-protein kinase $\mathrm{C}(\mathrm{PKC})$ - and NADPHoxidase-ROS generation is enhanced in diabetes (61). NADPH oxidase has been reported to be activated by glucose fluctuations to a greater extent than persistent hyperglycemia and contributes to the increase of ROS production (62). High levels of ROS induced by both constant high glucose and glucose fluctuations lead to different types of cell damages via different mechanisms and eventually permanent tissue damage.

\section{The injury of beta cells}

Pancreatic islet beta cells ( $\beta$-cells) play an important role in the balance of glucose homeostasis through regulating insulin secretion in response to changes in blood glucose concentrations (63). Various quantitative indices have been used to appropriately assess $\beta$-cell function, including HOMA2\%B index, and plasma $\mathrm{C}$-peptide during mixed-meal tolerance test (64). Glucagon is secreted from islet alpha-cells and controls glucose homeostasis in the fasting state (65). A recent clinical study showed that with the extension of glucose fluctuations in type 1 diabetics, glucagon secretory function was gradually impaired (66). Several experiments in vitro have reported that glucose fluctuations lead to significant impairment of $\beta$-cell function (67). Moreover, evidence from several clinical studies shows glucose fluctuations are involved in $\beta$-cell dysfunction $(68,69)$. Various strategies of blood glucose control can recover $\beta$-cell dysfunction which is impaired by glucose fluctuations in patients with both type 1 and type 2 diabetes $(70,71)$. Glucose fluctuations seem to aggravate $\beta$-cells dysfunction more seriously than persistent hyperglycemia (63). Glucose fluctuations have been reported to induce excessive formation of ROS, inflammatory cytokines, and oxidative stress, contributing to the apoptosis of $\beta$-cells (72). The $\beta$-cell apoptosis induced by both persistent hyperglycemia and glucose fluctuations is closely is closely related to the balance between pro-apoptotic $\mathrm{Bcl}-2$ proteins and anti-apoptotic $\mathrm{Bcl}$ proteins at the mitochondrial membrane $(73,74)$. Hyperglycemia has been reported to induce $\beta$-cell apoptosis through various signaling pathways, which is coupled with plasma membrane depolarization through the closure of $\mathrm{K}^{+}$channel and opening of $\mathrm{Ca}^{2+}$ channel in response to increased generation of adenosine triphosphate in type 2 diabetes (73). Moreover, Kim et al. (74) proposed that the glucose fluctuations-mediated downregulation of the anti-oxidative enzyme Mn-SOD and anti-apoptotic signal Bcl-2 may contribute to $\beta$-cell apoptosis. However, the precise molecular mechanisms by which glucose fluctuations induce $\beta$-cell apoptosis than persistent hyperglycaemia remains still unclear. Salvianolic acid B, as a component of Salvia miltiorrhiza, is reported to inhibit INS-1 cell apoptosis induced by intermittent high glucose. Salvianolic acid B can improve Bcl-2 family protein expression and preserve mitochondrial membrane potential by reducing oxidative stress. These findings suggest a potential clinical application of Salvianolic acid B in preventing the ongoing of $\beta$-cell dysfunction (75).

\section{The inflammation and apoptosis of cardiomyocytes}

ROS is a promoting factor for cardiac structural remodeling due to its influence in activating the TGF- $\beta$-mediated profibrotic signaling pathway, and in aggravating apoptosis, and inflammation (76). Shotaro et al. (27) established quantitative chronic blood glucose fluctuation models by experimentally fasting streptozotocin-induced type 1 diabetic rats for $24 \mathrm{~h}$ and injecting them with regular insulin additionally. Their results demonstrated that ROS levels were significantly higher in response to the induced glucose fluctuations than when compared to values for control treatments with persistent high glucose. High ROS levels contributed to the increase of TNF- $\alpha$ expression and TGF- $\beta 1$ expression, leading to increased inflammation, and apoptosis of cardiomyocytes (27). Consequently, the incidence of atrial fibrillation was apparently increased due to cardiac fibrosis and apoptosis in diabetic rats with glucose fluctuations (27). Ying et al. (77) held a similar view that cardiac fibrosis and oxidative stress were aggravated in diabetic rats exposed to glucose fluctuations. Further, high level of ROS can induce cardiomyocyte apoptosis via the activation of $\mathrm{Bcl}-2$-associated death promoter regulated by AKT. Along with increased ROS, inflammation and cardiac TNF- $\alpha$ were also increased more obviously in the experimental glucose fluctuation treatment rats, and both were involved the pathogenesis of diabetic complications (77). Thus, restoration of the balance of redox may be crucial in the treatment of cardiovascular complications.

\section{Endothelial dysfunction}

Glucose fluctuations can induce increased ROS generation in porcine iliac endothelial cells when compared to persistent high glucose, involved in the development of vascular complications (78). Increased endothelial oxidative stress induced by acute hyperglycemia may be related to concurrent activation of NADPH oxidase and consequential superoxide generation (79). Piconi et al. (80) proposed that both stable and oscillating blood glucose could increase oxidative stress and endothelial cell apoptosis through ROS overproduction resulting in the mitochondrial transport chain. In human retinal endothelial cells, the exposure to glucose fluctuations induces the overproduction of ROS at the mitochondrial transport chain level, leading to the development of DR. In this pathological process, over-expression of vascular endothelial growth factor (VEGF) due to excessive endothelial oxidative stress enhanced retinal endothelial cell proliferation (81). In vivo, Otsuka et al. (82) injected glucose via the femoral vein into rats after $12 \mathrm{~h}$ fasting in order to create a rapid rise of blood glucose. Experimental results revealed that reversible increases in monocyte adhesion were promoted by a temporary rise in blood glucose levels. A clinical study showed the consistent results that blood glucose fluctuations were consistently more 
likely to increase the vascular endothelial dysfunction in patients with type 2 diabetes compared with a group with persistent hyperglycemia by way of measuring the reactive hyperemia index, an index of vascular endothelial function (83).

\section{Neuronal damage}

As a member of the mitochondrial anion carrier protein family, uncoupling protein 2 (UCP2) plays a pivotal role in physiological and pathological adaptations of the nervous system (84). UCPs regulate mitochondrial homeostasis by helping to decrease mitochondrial ROS production as well as increasing mitochondrial proliferation and adenosine triphosphate production (85). Cardoso et al. (86) suggested that UCP2 influenced neuronal effects mediated by glucose level fluctuations and deemed UCP as a promising therapeutic strategy. Glucose transporters are located in the brain and involved in bidirectional processes of glucose transport (87). Mismatches between altered glucose transporters and acute glucose fluctuation events can contribute to the neuronal damage. During this process, oxidative stress plays a significant role in the pathophysiological changes in glucose neurotoxicity. Hence, Xie et al. (88) hypothesized that modulating hypoglycemia may improve neurological diabetic complications.

\section{Inflammation Involved in the Regulation of Diabetic Complications}

Inflammation is the primary physiological immune system reaction and plays an important role in the development and progression of diabetic complications (89). The activation of infiltrating inflammatory cells subsequently activates the cells of immune system and promotes the production of inflammatory mediators (90). The release of inflammatory mediators such as cytokine can be mediated by hyperglycemia and oxidative stress (91). Chronic inflammation and oxidative stress are inextricably linked via complex interactions of both mutual amplification in the pathophysiology of diabetes (92).

Moreover, glucose fluctuations have been reported to promote inflammation to a greater extent than persistent hyperglycemia (93). Quincozes-Santos et al. (94) proposed that glucose fluctuations in astroglial cells contributed to consequent cellular biomolecular damage by increasing oxidative stress and proinflammatory cytokine release.

\section{Signaling Pathways Implicated in Glucose Fluctuations}

Various kinds of signaling pathways are involved in the pathological process of diabetic complications induced by glucose fluctuations. These signaling pathways include protein kinase $\mathrm{C}(\mathrm{PKC})$, protein kinase $\mathrm{B}(\mathrm{AKT}), \mathrm{NF}-\kappa \mathrm{B}$, and the mitogen-activated protein kinase (MAPK) signaling pathway (Figure 1) (1). Oxidative stress and pro-inflammatory mediators can be trigger factors to activate these pathways (92).

\section{Activation of PKC}

PKC belongs to a family of protein kinases with more than 10 isoforms that have exerting functions as downstream targets for lipid second messengers. Overproduction of ROS

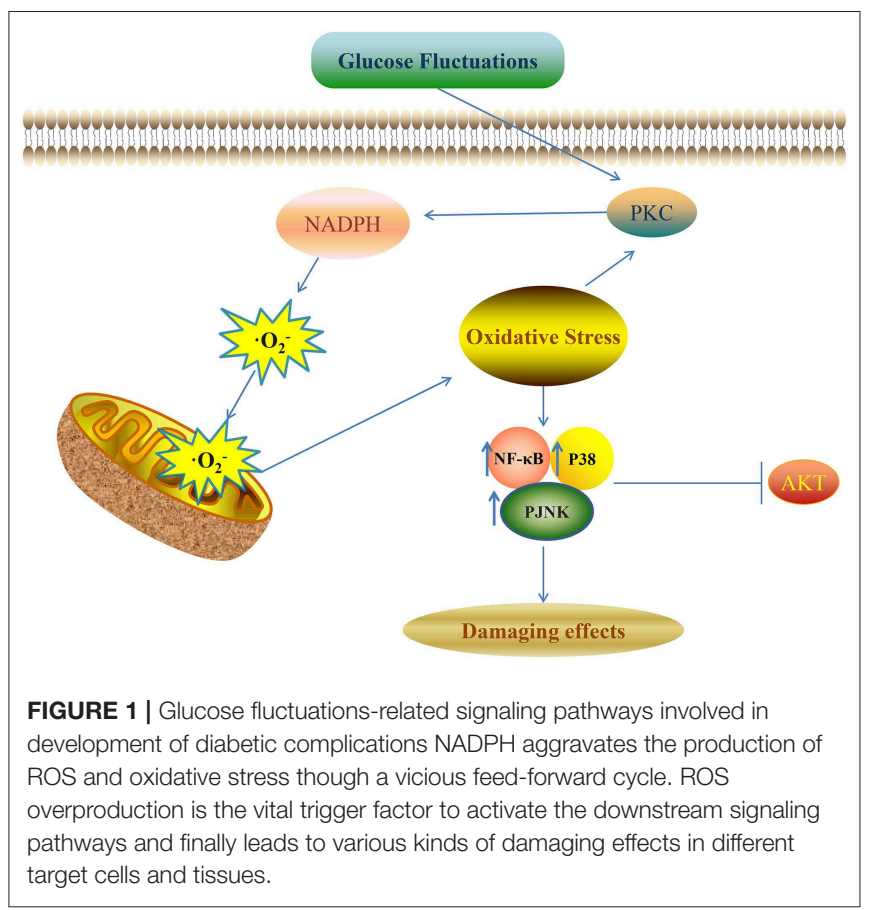

through PKC-dependent activation of NADPH oxidase in endothelial cells leads to the enhancement of endothelial cell apoptosis (95). Rats with type 2 diabetes were fed twice daily to induce repetitive postprandial glucose spikes and repetitive postprandial glucose fluctuations induced more monocyte adhesion to endothelium than stable hyperglycemia in aortic endothelium and the reduction of postprandial hyperglycemia could effectively improve these changes (96). Adhesion molecules function as a "molecular switch" that regulates the interaction between leukocytes and endothelium, and which is important in pathogenesis, and progress of atherogenesis. In particular, intracellular adhesion molecule-1 and vascular cell adhesion molecule-1 play significant roles in regulation of endothelial cell function (97). Glucose fluctuations can promote overproduction of adhesion molecules by activating PKC- $\beta$, completely dependent from mitochondrial superoxide over-production in human umbilical vein endothelial cells (98). $\mathrm{Na}$ et al. (99) suggested that PKC- $\beta$ II membrane translocation increased in endothelial cells with acute glucose fluctuations (100). The activation of JNK can be mediated by PKC- $\beta$ II and plays an important role in apoptosis of endothelial cells (101). PKC- $\beta$ II/JNK signaling pathways help regulate endothelial functions through mediating the downstream factors of cytokines and insulin signaling. Hence, the inhibitors of PKC and JNK may effectively reverse endothelia dysfunction induced by acute glucose fluctuations and should be considered further having potential for helping to prevent cardiovascular diseases.

Increased excessive superoxide formation in mitochondria can induce DNA damage by activating PKC and ataxiatelangiectasia mutated proteins (102). Schisano et al. (103) demonstrated that oscillating glucose up-regulated phospho- $\gamma$ histone $\mathrm{H} 2 \mathrm{AX}$ and $\mathrm{PKC}-\delta$ more effectively than constant high glucose, consequently leading to $\mathrm{p} 53$ phosphorylation. Activation 
of p53 after exposure to glucose fluctuations up-regulated the expression of genes involved in apoptosis, and seemed to be a more detrimental compared with a state of persistent hyperglycemia (104).

\section{Activation of AKT}

$\mathrm{AKT}$, as a pivotal signal transduction intermediate, is involved in the pathways of development of diabetic complications (105). Type 1 diabetic rats with fluctuated blood glucose were regularly injected with insulin $(6$ a.m., 12 p.m., and 6 p.m.) and glucose ( 9 a.m., 3 p.m., and 9 p.m.) over 12 weeks and the production of ROS was apparently enhanced due to blood glucose fluctuations and related to renal injury (16). Moreover, reduction of phosphorylated AKT leads to activation

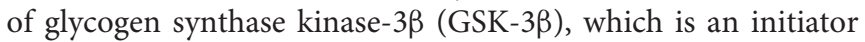
of cell death (106). Phosphorylated GSK-3 $\beta$ can activate NF$\kappa \mathrm{B}$ and caspase-3, leading to cardiomyocyte apoptosis (107). Wang et al. (108) proposed that glucose fluctuations can lead to oxidative stress injury in human umbilical vein endothelial cells through PI3K/AKT/GSK-3 $\beta$ pathway. Panax quinquefolius saponi (PQS), known as a Chinese herb, is widely used for diabetes treatment. PQS can reduce oxidative damage induced by glucose fluctuations via the PI3K/AKT/GSK-3 $\beta$ signaling pathway, which provides a potential treatment for improving diabetic cardiovascular complications (108). The AKT signaling pathway is also involved in insulin-dependent glucose uptake and utilization (109). Shao et al. (110) found that intermittent hyperglycemia can aggravate damage to tINS-1 cells more seriously than persistent hyperglycemia by suppressing insulin signaling. Phosphatase and tensin (PTEN), which is located on chromosome 10 plays an important role in regulating cell apoptosis by dephosphorylating PI3K-produced IP3. AKT phosphorylation is dependent on IP3 directly. PTEN expression is increased in the condition of glucose fluctuations and leads to the decrease of $\mathrm{p}$-AKT levels, mediating the $\beta$-cells injury. Biscetti et al. (111) indicated that oxidative stress played a critical role in the pathogenesis of intermittenthyperglycemia-related endothelial dysfunction. Increased ROS levels, along with decreased VEGF and AKT phosphorylation contribute to endothelial dysfunction and damaged collateral vessel formation.

\section{MAPKs Signaling Pathway}

MAPKs are a family of four major characterized subfamilies including ERK1/2, p38, JNK, and ERK5 (112). The MAPK signaling pathway can be activated not only by high glucose but also by glucose fluctuations. ROS and pro-inflammatory cytokines may be trigger factors. Ye et al. (113) showed that blood glucose fluctuation is involved in skin collagen metabolism by regulating the MAPK and Smad signaling pathways. P38 MAPK consists of four structurally homologous isoforms $(\alpha, \beta, \gamma, \delta)$ and each isoform is sensitive to pharmacological inhibition differently (114). In the condition of glucose fluctuations, p38 signaling pathway activation is involved in ROS overproduction, mitochondrial dysfunction, and cell proliferation with consequent cellular damage in astroglial cells (94). Rutin, belonging to the flavonoid family, is reported to effectively reduce the vascular smooth muscle cell migration, and proliferation induced by intermittent hyperglycemia (115). Rutin can decrease ROS production, phospho-NF- $\mathrm{KB}$ and phosphorylation of MAPK (ERK1/2) and PI3K. Further, antioxidative and anti-atherosclerotic properties of rutin can be a potential treatment for diabetic patients with cardiovascular complications (115). P38 MAPK inhibitors have been used in clinical studies for cardiovascular diseases in patients with diabetes (116). However, it remains unclear that the effects of inhibiting MAPK signaling in diabetes with glucose fluctuations and further studies are needed to explore new effective treatments. NF-кB is part of ubiquitous family including several transcription factors that regulate the expression of genes in related processes such as oxidative stress, inflammation, and apoptosis (117). Zhang et al. (118) demonstrated that increased myocardial apoptosis after exposure to acute blood glucose fluctuations was associated with enhanced oxidative stress and activation of NF- $\kappa$ B.

\section{Dysregulation of microRNAs}

MicroRNAs (miRNAs) are known to be short non-coding genes. Recent researches indicate that miRNAs may function as important regulators in modulation of diabetic complications. MiRNAs play significant roles in various biological processes by inducing inhibition of protein synthesis or the degradation of mRNA (119). Saito et al. (120) proposed that miRNA-200c and miRNA-141 expression levels were abundant in heart tissues of type 1 diabetic rats with glucose fluctuations, leading to an increase in ROS levels, and an aggravated ischemia/reperfusion injury state in the diabetic heart. Guo et al. (121) have found that miRNA-1273g-3p was significantly upregulated in human umbilical vein endothelial cells (fluctuations between 5 and $25 \mathrm{mmol} / \mathrm{L}$ ) compared with sustained high glucose, leading to dysfunction of human umbilical vein endothelial cells. Moreover, miR-1273g-3p plays an important role in regulating cell proliferation and migration after exposure to treatment of glucose fluctuations. Further studies are expected which will explore regulation of miRNA under condition of glucose fluctuations and subsequent miRNAbased therapies may emerge as potentially important treatments for patients.

\section{CURRENT TREATMENT STRATEGIES TARGETING GLUCOSE FLUCTUATIONS}

\section{Early Insulin Therapy}

Several clinical studies have supported that early and appropriate insulin treatment may reduce harmful effects on $\beta$-cells induced by glucose fluctuations in both type 1 and type 2 diabetic patients (122-124). In newly diagnosed type 2 diabetes, early intensive insulin therapy has been reported to maintain extended glycaemic remission and recover $\beta$-cell function more effectively compared with oral hypoglycaemic agents (122). Moreover, Pennartz et al. (123) reported that basal treatment with long-acting insulin for patients with type 2 diabetes improved postprandial insulin secretion. A study by Bruttomesso et al. (124) in type 1 diabetes indicated 
that continuous subcutaneous insulin infusion reduced glucose variability and increased glycaemic control and treatment satisfaction compared with multiple daily injections with glargine. More recently, Bailey et al. (125) have found that insulin glargine $300 \mathrm{U} / \mathrm{mL}$ decreases the fluctuations in pharmacodynamic profiles and increases the uniform distribution of pharmacokinetic profiles, compared with insulin degludec $100 \mathrm{U} / \mathrm{mL}$ in a morning administration of $0.4 \mathrm{U} / \mathrm{kg} /$ day in type 1 diabetes.

\section{Continuous Glucose Monitoring Systems}

Continuous glucose monitoring systems have been more and more increasingly used for insulin-requiring diabetic patients to monitor glucose fluctuations (126). Continuous glucose monitoring systems help diabetic patients in regulating their lifestyle and medication adjustments (127, 128). Collectively, continuous glucose monitoring seems to be an important tool with appropriate patient education to improve glycaemic stability for patients with type 1 and type 2 diabetes mellitus $(129,130)$.

Data from several clinical studies showed that implantable insulin pump therapy contributed to the improvement of controlling overall quality of blood glucose concentrations in diabetes (131). Moreover, administration of insulin via insulin pump together with continuous glucose monitoring improves glucose fluctuations more than conventional pump therapy in poorly controlled type 1 diabetic patients (132).

\section{CONCLUSION}

In summary, glucose fluctuations appear as an important risk factor in the diabetic population. More and more clinical and experimental studies have been conducted to explore the molecular mechanisms of glucose-fluctuation-induced damaging effects. Excessive oxidative stress and inflammation which seems resultant from glucose fluctuations is involved in the development and progression of diabetic complications. Moreover, ROS can be a vital factor to triggering the activation of downstream signaling pathways, including PKC, AKT, NF-кB, and MAPK signaling pathways such to eventually cause various kinds of damaging effects in different target cells and tissues. Some miRNAs are also involved in regulation on the state of glucose fluctuations and may also have potential for use in clinical treatment. Hence, continued research that helps to further understand glucose-fluctuation-related molecular mechanisms likely will be important for developing new clinical treatments in the future.

\section{AUTHOR CONTRIBUTIONS}

Z-YZ and L-FM wrote the initial drafts. L-LQ, NW, M-MQ, and Y-MZ edited the manuscript. R-XW, S-PD, and YW revised the review and finalized the last version of the article. All authors checked and approved the submitted version.

\section{FUNDING}

This study was supported by grants from the National Natural Science Foundation of China (81770331, 81500249, 81400297, and 81500323) and Natural Science Foundation of Jiangsu Province (BK20151110), Jiangsu province Young Medical Talents (QNRC2016185 and QNRC2016186), Postgraduate Research \& Practice Innovation Program of Jiangsu Province (KYCX17_1305).

\section{REFERENCES}

1. Volpe CMO, Villar-Delfino PH, Dos Anjos PMF, Nogueira-Machado JA. Cellular death, reactive oxygen species (ROS) and diabetic complications. Cell Death Dis. (2018) 9:119. doi: 10.1038/s41419-017-0135-z

2. Ceriello A, Kilpatrick ES. Glycemic variability: both sides of the story. Diabetes Care. (2013) 36(Suppl. 2):S272-5. doi: 10.2337/dcS13-2030

3. Cavalot F. Do data in the literature indicate that glycaemic variability is a clinical problem? Glycaemic variability and vascular complications of diabetes. Diabetes Obes Metab. (2013) 15(Suppl. 2):3-8. doi: 10.1111/dom.12140

4. Rodbard D. New and improved methods to characterize glycemic variability using continuous glucose monitoring. Diabetes Technol Ther. (2009) 11:55165. doi: $10.1089 /$ dia.2009.0015

5. Monnier L, Colette C, Owens DR. Glycemic variability: the third component of the dysglycemia in diabetes. Is it important? how to measure it? J Diabetes Sci Technol. (2008) 2:1094-100. doi: 10.1177/193229680800200618

6. Yu X, Lin L, Shen J, Chen Z, Jian J, Li B, et al. Calculating the mean amplitude of glycemic excursions from continuous glucose data using an open-code programmable algorithm based on the integer nonlinear method. Comput Math Methods Med. (2018) 2018:6286893. doi: 10.1155/2018/6286893

7. Akasaka T, Sueta D, Tabata N, Takashio S, Yamamoto E, Izumiya $\mathrm{Y}$, et al. Effects of the mean amplitude of glycemic excursions and vascular endothelial dysfunction on cardiovascular events in nondiabetic patients with coronary artery disease. J Am Heart Assoc. (2017) 6:e004841. doi: 10.1161/JAHA.116.004841

8. Okazaki T, Hifumi T, Kawakita K, Shishido H, Ogawa D, Okauchi M, et al. Blood glucose variability: a strong independent predictor of neurological outcomes in aneurysmal subarachnoid hemorrhage. J Intensive Care Med. (2018) 33:189-95. doi: 10.1177/0885066616669328

9. Iwasaki S, Kozawa J, Fukui K, Iwahashi H, Imagawa A, Shimomura I. Coefficient of variation of R-R interval closely correlates with glycemic variability assessed by continuous glucose monitoring in insulin-depleted patients with type 1 diabetes. Diabetes Res Clin Pract. (2015) 109:397403. doi: 10.1016/j.diabres.2015.05.021

10. Hwang JJ, Jiang L, Sanchez Rangel E, Fan X, Ding Y, Lam W, et al. Glycemic variability and brain glucose levels in type 1 diabetes. Diabetes. (2019) 68:163-71. doi: 10.2337/db18-0722

11. Li LQ, Yao MY, Ma JX, Xue P, Li YK. Continuous subcutaneous insulin infusion combined with liraglutide reduced glycemic variability and oxidative stress in type 2 diabetes mellitus: a study based on the flash glucose monitoring system. Endocr J. (2019). doi: 10.1507/endocrj.EJ19-0016. [Epub ahead of print].

12. Joshi A, Mitra A, Anjum N, Shrivastava N, Khadanga S, Pakhare A, et al. Patterns of glycemic variability during a diabetes self-management educational program. Med Sci. (2019) 7:E52. doi: 10.3390/medsci70 30052

13. Yang YF, Li TC, Li CI, Liu CS, Lin WY, Yang SY, et al. Visit-tovisit glucose variability predicts the development of end-stage renal disease in type 2 diabetes: 10-year follow-up of taiwan diabetes study. Medicine. (2015) 94:e1804. doi: 10.1097/MD.0000000000 001804 
14. Jin YP, Su XF, Yin GP, Xu XH, Lou JZ, Chen JJ, et al. Blood glucose fluctuations in hemodialysis patients with end stage diabetic nephropathy. J Diabetes Complicat. (2015) 29:395-9. doi: 10.1016/j.jdiacomp.2014.12.015

15. Cheng X, Gao W, Dang Y, Liu X, Li Y, Peng X, et al. Both ERK/MAPK and TGF-Beta/Smad signaling pathways play a role in the kidney fibrosis of diabetic mice accelerated by blood glucose fluctuation. J Diabetes Res. (2013) 2013:463740. doi: 10.1155/2013/463740

16. Ying C, Zhou X, Chang Z, Ling H, Cheng X, Li W. Blood glucose fluctuation accelerates renal injury involved to inhibit the AKT signaling pathway in diabetic rats. Endocrine. (2016) 53:81-96. doi: 10.1007/s12020-016-0867-z

17. Yau JWY, Rogers SL, Kawasaki R, Lamoureux EL, Kowalski JW, Bek T, et al. Global prevalence and major risk factors of diabetic retinopathy. Diabetes Care. (2012) 35:556-64. doi: 10.2337/dc11-1909

18. Picconi F, Parravano M, Ylli D, Pasqualetti P, Coluzzi S, Giordani I, et al. Retinal neurodegeneration in patients with type 1 diabetes mellitus: the role of glycemic variability. Acta Diabetol. (2017) 54:48997. doi: 10.1007/s00592-017-0971-4

19. Takao T, Ide T, Yanagisawa H, Kikuchi M, Kawazu S, Matsuyama Y. The effect of fasting plasma glucose variability on the risk of retinopathy in type 2 diabetic patients: retrospective long-term follow-up. Diabetes Res Clin Pract. (2010) 89:296-302. doi: 10.1016/j.diabres.2010.03.027

20. American Diabetes Association (6) Glycemic targets. Diabetes Care. (2015) 38:S33-40. doi: 10.2337/dc15-S009

21. Hu YM, Zhao LH, Zhang XL, Cai HL, Huang HY, Xu F, et al. Association of glycaemic variability evaluated by continuous glucose monitoring with diabetic peripheral neuropathy in type 2 diabetic patients. Endocrine. (2018) 60:292-300. doi: 10.1007/s12020-018-1546-Z

22. Kwai NC, Arnold R, Poynten AM, Krishnan AV. Association between glycemic variability and peripheral nerve dysfunction in type 1 diabetes. Muscle Nerve. (2016) 54:967-9. doi: 10.1002/mus.25274

23. Nyiraty S, Pesei F, Orosz A, Coluzzi S, Vagi OE, Lengyel C, et al. Cardiovascular autonomic neuropathy and glucose variability in patients with type 1 diabetes: is there an association? Front Endocrinol. (2018) 9:174. doi: 10.3389/fendo.2018.00174

24. Fleischer J, Lebech Cichosz S, Hoeyem P, Laugesen E, Loegstrup Poulsen P, Sandahl Christiansen J, et al. Glycemic variability is associated with reduced cardiac autonomic modulation in women with type 2 diabetes. Diabetes Care. (2015) 38:682-8. doi: 10.2337/dc15-er11

25. Siegelaar SE, Kilpatrick ES, Rigby AS, Atkin SL, Hoekstra JB, Devries JH. Glucose variability does not contribute to the development of peripheral and autonomic neuropathy in type 1 diabetes: data from the DCCT. Diabetologia. (2009) 52:2229-32. doi: 10.1007/s00125-009-1473-x

26. Lazzeri C, Valente S, Chiostri M, D’Alfonso MG, Gensini GF. Prognostic impact of early glucose variability in acute heart failure patients: a pilot study. Int J Cardiol. (2014) 177:693-5. doi: 10.1016/j.ijcard.2014.09.150

27. Saito S, Teshima Y, Fukui A, Kondo H, Nishio S, Nakagawa M, et al. Glucose fluctuations increase the incidence of atrial fibrillation in diabetic rats. Cardiovasc Res. (2014) 104:5-14. doi: 10.1093/cvr/cvu176

28. Zhang XG, Zhang YQ, Zhao DK, Wu JX, Zhao J, Jiao XM, et al. Relationship between blood glucose fluctuation and macrovascular endothelial dysfunction in type 2 diabetic patients with coronary heart disease. Eur Rev Med Pharmacol Sci. (2014) 18: 3593-600.

29. Zhang $\mathrm{X}, \mathrm{Xu} \mathrm{X}$, Jiao $\mathrm{X}$, Wu J, Zhou S, Lv X. The effects of glucose fluctuation on the severity of coronary artery disease in type 2 diabetes mellitus. J Diabetes Res. (2013) 2013:576916. doi: 10.1155/2013/5 76916

30. Huang J, Zhang X, Li J, Tang L, Jiao X, Lv X. Impact of glucose fluctuation on acute cerebral infarction in type 2 diabetes. Can J Neurol Sci. (2014) 41:486-92. doi: 10.1017/S0317167100018539

31. Yoon JE, Sunwoo JS, Kim JS, Roh H, Ahn MY, Woo HY, et al. Poststroke glycemic variability increased recurrent cardiovascular events in diabetic patients. J Diabetes Complicat. (2017) 31:390-4. doi: 10.1016/j.jdiacomp.2016.11.014

32. Kinoshita T, Shimoda M, Sanada J, Fushimi Y, Hirata Y, Irie S, et al. Association of $\mathrm{GA} / \mathrm{HbAlc}$ ratio and cognitive impairment in subjects with type 2 diabetes mellitus. J Diabetes Complicat. (2016) 30:14525. doi: 10.1016/j.jdiacomp.2016.08.008
33. Cui X, Abduljalil A, Manor BD, Peng CK, Novak V. Multi-scale glycemic variability: a link to gray matter atrophy and cognitive decline in type 2 diabetes. PLoS ONE. (2014) 9:e86284. doi: 10.1371/journal.pone.0086284

34. Seddon M, Looi YH, Shah AM. Oxidative stress and redox signalling in cardiac hypertrophy and heart failure. Heart. (2007) 93:903-7. doi: 10.1136/hrt.2005.068270

35. Wold LE, Ceylan-Isik AF, Ren J. Oxidative stress and stress signaling: menace of diabetic cardiomyopathy. Acta Pharmacologica Sinica. (2005) 26:908-17. doi: 10.1111/j.1745-7254.2005.00146.x

36. Evans JL, Goldfine ID, Maddux BA, Grodsky GM. Are oxidative stressactivated signaling pathways mediators of insulin resistance and beta-cell dysfunction? Diabetes. (2003) 52:1-8. doi: 10.2337/diabetes.52.1.1

37. Hoeldtke RD, Bryner KD, McNeill DR, Warehime SS, Van Dyke K, Hobbs G. Oxidative stress and insulin requirements in patients with recent-onset type 1 diabetes. J Clin Endocrinol Metab. (2003) 88:16248. doi: 10.1210/jc.2002-021525

38. Monnier L, Mas E, Ginet C, Michel F, Villon L, Cristol JP, et al. Activation of oxidative stress by acute glucose fluctuations compared with sustained chronic hyperglycemia in patients with type 2 diabetes. JAMA. (2006) 295:1681-7. doi: 10.1001/jama.295.14.1681

39. Ceriello A, Esposito K, Piconi L, Ihnat MA, Thorpe JE, Testa R, et al. Oscillating glucose is more deleterious to endothelial function and oxidative stress than mean glucose in normal and type 2 diabetic patients. Diabetes. (2008) 57:1349-54. doi: 10.2337/db08-0063

40. Ohara M, Nagaike H, Goto S, Fukase A, Tanabe Y, Tomoyasu $\mathrm{M}$, et al. Improvements of ambient hyperglycemia and glycemic variability are associated with reduction in oxidative stress for patients with type 2 diabetes. Diabetes Res Clin Pract. (2018) 139:253-61. doi: 10.1016/j.diabres.2018.02.017

41. Wentholt IM, Kulik W, Michels RP, Hoekstra JB, DeVries JH. Glucose fluctuations and activation of oxidative stress in patients with type 1 diabetes. Diabetologia. (2008) 51:183-90. doi: 10.1007/s00125-0070842-6

42. Maritim AC, Sanders RA, Watkins JB, 3rd. Diabetes, oxidative stress, and antioxidants: a review. J Biochem Mol Toxicol. (2003) 17:2438. doi: 10.1002/jbt.10058

43. Kaczmarczyk-Sedlak I, Folwarczna J, Sedlak L, Zych M, Wojnar W, Szuminska I, et al. Effect of caffeine on biomarkers of oxidative stress in lenses of rats with streptozotocin-induced diabetes. Arch Med Sci. (2019) 15:1073-80. doi: 10.5114/aoms.2019.85461

44. Sun X, Pan H, Tan H, Yu Y. High free fatty acids level related with cardiac dysfunction in obese rats. Diabetes Res Clin Pract. (2012) 95:2519. doi: 10.1016/j.diabres.2011.10.028

45. Shukla R, Banerjee S, Tripathi YB. Antioxidant and antiapoptotic effect of aqueous extract of Pueraria tuberosa (Roxb. Ex Willd.) DC. On streptozotocin-induced diabetic nephropathy in rats. BMC Complement Altern Med. (2018) 18:156. doi: 10.1186/s12906-018-2221-x

46. Yang H, Fan S, Song D, Wang Z, Ma S, Li S, et al. Long-term streptozotocininduced diabetes in rats leads to severe damage of brain blood vessels and neurons via enhanced oxidative stress. Mol Med Rep. (2013) 7:43140. doi: 10.3892/mmr.2012.1227

47. Gao Y, Zhang RR, Li JH, Ren M, Ren ZX, Shi JH, et al. Radix astragali lowers kidney oxidative stress in diabetic rats treated with insulin. Endocrine. (2012) 42:592-8. doi: 10.1007/s12020-012-9670-7

48. Arthur JR. The glutathione peroxidases. Cell Mol Life Sci. (2000) 57:182535. doi: 10.1007/PL00000664

49. Lewis P, Stefanovic N, Pete J, Calkin AC, Giunti S, Thallas-Bonke $\mathrm{V}$, et al. Lack of the antioxidant enzyme glutathione peroxidase-1 accelerates atherosclerosis in diabetic apolipoprotein E-deficient mice. Circulation. (2007) 115:2178-87. doi: 10.1161/CIRCULATIONAHA.106. 664250

50. Kim HR, Choi EJ, Kie JH, Lee JH, Seoh JY. Deficiency of glutathione peroxidase-1 and catalase attenuated diet-induced obesity and associated metabolic disorders. Acta Diabetol. (2019). doi: 10.1007/s00592-019-01388-5. [Epub ahead of print].

51. Zschauer TC, Matsushima S, Altschmied J, Shao D, Sadoshima J, Haendeler J. Interacting with thioredoxin-1-disease or no disease? Antioxid Redox Signal. (2013) 18:1053-62. doi: 10.1089/ars.2012.4822 
52. Whayne TF Jr, Parinandi N, Maulik N. Thioredoxins in cardiovascular disease. Can J Physiol Pharmacol. (2015) 93:90311. doi: 10.1139/cjpp-2015-0105

53. Luan R, Liu S, Yin T, Lau WB, Wang Q, Guo W, et al. High glucose sensitizes adult cardiomyocytes to ischaemia/reperfusion injury through nitrative thioredoxin inactivation. Cardiovasc Res. (2009) 83:294302. doi: $10.1093 / \mathrm{cvr} / \mathrm{cvp} 085$

54. Ji L, Wang Q, Huang F, An T, Guo F, Zhao Y, et al. FOXO1 overexpression attenuates tubulointerstitial fibrosis and apoptosis in diabetic kidneys by ameliorating oxidative injury via TXNIP-TRX. Oxid Med Cell Longev. (2019) 2019:3286928. doi: 10.1155/2019/3286928

55. Zhou C, Routh VH. Thioredoxin-1 overexpression in the ventromedial nucleus of the hypothalamus preserves the counterregulatory response to hypoglycemia during type 1 diabetes in male rats. Diabetes. (2018) 67:12030. doi: $10.2337 / \mathrm{db} 17-0930$

56. Fang $\mathrm{S}$, Jin $\mathrm{Y}$, Zheng $\mathrm{H}$, Yan J, Cui $\mathrm{Y}, \mathrm{Bi} \mathrm{H}$, et al. High glucose condition upregulated Txnip expression level in rat mesangial cells through ROS/MEK/MAPK pathway. Mol Cell Biochem. (2011) 347:17582. doi: $10.1007 /$ s11010-010-0626-z

57. Jiang Q. Natural forms of vitamin E: metabolism, antioxidant, and antiinflammatory activities and their role in disease prevention and therapy. Free Radic Biol Med. (2014) 72:76-90. doi: 10.1016/j.freeradbiomed.2014.03.035

58. Mescic Macan A, Gazivoda Kraljevic T, Raic-Malic S. Therapeutic perspective of vitamin C and its derivatives. Antioxidants. (2019) 8:E247. doi: 10.3390/antiox8080247

59. Maia A, Oliveira J, Lajnef M, Mallet L, Tamouza R, Leboyer M, et al. Oxidative and nitrosative stress markers in obsessive-compulsive disorder: a systematic review and meta-analysis. Acta Psychiatr Scand. (2019) 139:42033. doi: 10.1111/acps.13026

60. Sourris KC, Harcourt BE, Tang PH, Morley AL, Huynh K, Penfold SA, et al. Ubiquinone (coenzyme Q10) prevents renal mitochondrial dysfunction in an experimental model of type 2 diabetes. Free Radic Biol Med. (2012) 52:716-23. doi: 10.1016/j.freeradbiomed.2011.11.017

61. Huynh K, Bernardo BC, McMullen JR, Ritchie RH. Diabetic cardiomyopathy: mechanisms and new treatment strategies targeting antioxidant signaling pathways. Pharmacol Ther. (2014) 142:375-415. doi: 10.1016/j.pharmthera.2014.01.003

62. Abdelzaher LA, Imaizumi T, Suzuki T, Tomita K, Takashina M, Hattori Y. Astaxanthin alleviates oxidative stress insults-related derangements in human vascular endothelial cells exposed to glucose fluctuations. Life Sci. (2016) 150:24-31. doi: 10.1016/j.lfs.2016.02.087

63. Kohnert KD, Freyse EJ, Salzsieder E. Glycaemic variability and pancreatic beta-cell dysfunction. Curr Diabetes Rev. (2012) 8:345-54. doi: 10.2174/157339912802083513

64. Lopez S, Bermudez B, Pacheco YM, Villar J, Abia R, Muriana FJ. Distinctive postprandial modulation of beta cell function and insulin sensitivity by dietary fats: monounsaturated compared with saturated fatty acids. Am J Clin Nutr. (2008) 88:638-44. doi: 10.1093/ajcn/88.3.638

65. Girard J. Glucagon, a key factor in the pathophysiology of type 2 diabetes. Biochimie. (2017) 143:33-6. doi: 10.1016/j.biochi.2017.10.004

66. Li K, Song WJ, Wu X, Gu DY, Zang P, Gu P, et al. Associations of serum glucagon levels with glycemic variability in type 1 diabetes with different disease durations. Endocrine. (2018) 61:473-81. doi: 10.1007/s12020-018-1641-1

67. Shao C, Gu J, Meng X, Zheng H, Wang D. Systematic investigation into the role of intermittent high glucose in pancreatic beta-cells. Int J Clin Exp Med. (2015) 8:5462-9.

68. Murata M, Adachi H, Oshima S, Kurabayashi M. Glucose fluctuation and the resultant endothelial injury are correlated with pancreatic beta cell dysfunction in patients with coronary artery disease. Diabetes Res Clin Pract. (2017) 131:107-15. doi: 10.1016/j.diabres.2017.07.007

69. Kohnert KD, Heinke P, Vogt L, Augstein P, Salzsieder E. Declining ss-cell function is associated with the lack of long-range negative correlation in glucose dynamics and increased glycemic variability: a retrospective analysis in patients with type 2 diabetes. J Clin Transl Endocrinol. (2014) 1:1929. doi: 10.1016/j.jcte.2014.09.003

70. Takai M, Anno T, Kawasaki F, Kimura T, Hirukawa H, Mune $\mathrm{T}$, et al. Association of the glycemic fluctuation as well as glycemic control with the pancreatic beta-cell function in japanese subjects with type 2 diabetes mellitus. Intern Med. (2019) 58:167-73. doi: 10.2169/internalmedicine.1053-18

71. Levetan C, Want LL, Weyer C, Strobel SA, Crean J, Wang Y, et al. Impact of pramlintide on glucose fluctuations and postprandial glucose, glucagon, and triglyceride excursions among patients with type 1 diabetes intensively treated with insulin pumps. Diabetes Care. (2003) 26:18. doi: 10.2337/diacare.26.1.1

72. Shi XL, Ren YZ, Wu J. Intermittent high glucose enhances apoptosis in INS-1 cells. Exp Diabetes Res. (2011) 2011:754673. doi: 10.1155/2011/754673

73. Tomita T. Apoptosis in pancreatic beta-islet cells in Type 2 diabetes. Bosn J Basic Med Sci. (2016) 16:162-79. doi: 10.17305/bjbms.2016.919

74. Kim MK, Jung HS, Yoon CS, Ko JH, Jun HJ, Kim TK, et al. The effect of glucose fluctuation on apoptosis and function of INS-1 pancreatic beta cells. Korean Diabetes J. (2010) 34:47-54. doi: 10.4093/kdj.2010. 34.1.47

75. Tao S, Ren Y, Zheng H, Zhao M, Zhang X, Zhu Y, et al. Salvianolic acid B inhibits intermittent high glucose-induced INS-1 cell apoptosis through regulation of Bcl-2 proteins and mitochondrial membrane potential. Eur J Pharmacol. (2017) 814:56-62. doi: 10.1016/j.ejphar.2017.08.007

76. Jain M, Rivera S, Monclus EA, Synenki L, Zirk A, Eisenbart J, et al. Mitochondrial reactive oxygen species regulate transforming growth factorbeta signaling. J Biol Chem. (2013) 288:770-7. doi: 10.1074/jbc.M112. 431973

77. Ying C, Liu T, Ling H, Cheng M, Zhou X, Wang S, et al. Glucose variability aggravates cardiac fibrosis by altering AKT signalling path. Diab Vasc Dis Res. (2017) 14:327-35. doi: 10.1177/1479164117698917

78. Ge QM, Dong Y, Zhang HM, Su Q. Effects of intermittent high glucose on oxidative stress in endothelial cells. Acta Diabetol. (2010) 47(Suppl 1):97103. doi: 10.1007/s00592-009-0140-5

79. Yano M, Hasegawa G, Ishii M, Yamasaki M, Fukui M, Nakamura N, et al. Short-term exposure of high glucose concentration induces generation of reactive oxygen species in endothelial cells: implication for the oxidative stress associated with postprandial hyperglycemia. Redox Rep. (2004) 9:1116. doi: 10.1179/135100004225004779

80. Piconi L, Quagliaro L, Assaloni R, Da Ros R, Maier A, Zuodar G, et al. Constant and intermittent high glucose enhances endothelial cell apoptosis through mitochondrial superoxide overproduction. Diabetes Metab Res Rev. (2006) 22:198-203. doi: 10.1002/dmrr.613

81. Sun J, Xu Y, Sun S, Sun Y, Wang X. Intermittent high glucose enhances cell proliferation and VEGF expression in retinal endothelial cells: the role of mitochondrial reactive oxygen species. Mol Cell Biochem. (2010) 343:2735. doi: 10.1007/s11010-010-0495-5

82. Otsuka A, Azuma K, Iesaki T, Sato F, Hirose T, Shimizu T, et al. Temporary hyperglycaemia provokes monocyte adhesion to endothelial cells in rat thoracic aorta. Diabetologia. (2005) 48:2667-74. doi: 10.1007/s00125-005-0005-6

83. Torimoto K, Okada Y, Mori H, Tanaka Y. Relationship between fluctuations in glucose levels measured by continuous glucose monitoring and vascular endothelial dysfunction in type 2 diabetes mellitus. Cardiovasc Diabetol. (2013) 12:1. doi: 10.1186/1475-2840-12-1

84. Cardoso S, Correia S, Carvalho C, Candeias E, Placido AI, Duarte AI, et al. Perspectives on mitochondrial uncoupling proteins-mediated neuroprotection. J Bioenerg Biomembr. (2015) 47:119-31. doi: 10.1007/s10863-014-9580-x

85. Andrews ZB, Diano S, Horvath TL. Mitochondrial uncoupling proteins in the CNS: in support of function and survival. Nat Rev Neurosci. (2005) 6:829-40. doi: 10.1038/nrn1767

86. Cardoso S, Seica RM, Moreira PI. Uncoupling protein 2 inhibition exacerbates glucose fluctuation-mediated neuronal effects. Neurotox Res. (2018) 33:388-401. doi: 10.1007/s12640-017-9805-y

87. Wood IS, Trayhurn P. Glucose transporters (GLUT and SGLT): expanded families of sugar transport proteins. Br J Nutr. (2003) 89:3-9. doi: 10.1079/BJN2002763

88. Xie Z, Guo J, Kang Y, Ou X. Mismatch between GLUTs and glucose levels causes neuronal damage during glucose fluctuations. Med Hypotheses. (2018) 112:37-9. doi: 10.1016/j.mehy.2018. 01.010 
89. Lontchi-Yimagou E, Sobngwi E, Matsha TE, Kengne AP. Diabetes mellitus and inflammation. Curr Diab Rep. (2013) 13:435-44. doi: 10.1007/s11892-013-0375-y

90. Muriach M, Flores-Bellver M, Romero FJ, Barcia JM. Diabetes and the brain: oxidative stress, inflammation, and autophagy. Oxid Med Cell Longev. (2014) 2014:102158. doi: 10.1155/2014/102158

91. Gumieniczek A, Hopkala H, Rolinski J, Bojarska-Junak A. Antioxidative and anti-inflammatory effects of repaglinide in plasma of diabetic animals. Pharmacol Res. (2005) 52:162-6. doi: 10.1016/j.phrs.2005.02.019

92. Oguntibeju OO. Type 2 diabetes mellitus, oxidative stress and inflammation: examining the links. Int J Physiol Pathophysiol Pharmacol. (2019) 11:45-63.

93. Wu N, Shen H, Liu H, Wang Y, Bai Y, Han P. Acute blood glucose fluctuation enhances rat aorta endothelial cell apoptosis, oxidative stress and pro-inflammatory cytokine expression in vivo. Cardiovasc Diabetol. (2016) 15:109. doi: 10.1186/s12933-016-0427-0

94. Quincozes-Santos A, Bobermin LD, de Assis AM, Goncalves CA, Souza DO. Fluctuations in glucose levels induce glial toxicity with glutamatergic, oxidative and inflammatory implications. Biochim Biophys Acta Mol Basis Dis. (2017) 1863:1-14. doi: 10.1016/j.bbadis.2016.09.013

95. Quagliaro L, Piconi L, Assaloni R, Martinelli L, Motz E, Ceriello A. Intermittent high glucose enhances apoptosis related to oxidative stress in human umbilical vein endothelial cells: the role of protein kinase C and NAD(P)H-oxidase activation. Diabetes. (2003) 52:2795804. doi: $10.2337 /$ diabetes.52.11.2795

96. Azuma K. Repetitive fluctuations in blood glucose enhance monocyte adhesion to the endothelium of rat thoracic aorta. Arterioscler Thromb Vasc Biol. (2006) 26:2275-80. doi: 10.1161/01.ATV.0000239488.05069.03

97. Kado S, Wakatsuki T, Yamamoto $M$, Nagata $N$. Expression of intercellular adhesion molecule-1 induced by high glucose concentrations in human aortic endothelial cells. Life Sci. (2001) 68:727-37. doi: 10.1016/S0024-3205(00)00968-1

98. Quagliaro L, Piconi L, Assaloni R, Da Ros R, Maier A, Zuodar $\mathrm{G}$, et al. Intermittent high glucose enhances ICAM-1, VCAM1 and E-selectin expression in human umbilical vein endothelial cells in culture: the distinct role of protein kinase $\mathrm{C}$ and mitochondrial superoxide production. Atherosclerosis. (2005) 183:259-67. doi: 10.1016/j.atherosclerosis.2005.03.015

99. Wu N, Shen H, Wang Y, He B, Zhang Y, Bai Y, et al. Role of the PKCbetaII/JNK signaling pathway in acute glucose fluctuation-induced apoptosis of rat vascular endothelial cells. Acta Diabetol. (2017) 54:72736. doi: 10.1007/s00592-017-0999-5

100. Yamawaki H, Saito K, Okada M, Hara Y. Methylglyoxal mediates vascular inflammation via JNK and p38 in human endothelial cells. Am J Physiol Cell Physiol. (2008) 295:C1510-7. doi: 10.1152/ajpcell.00252.2008

101. Liu W, Schoenkerman A, Lowe WL Jr. Activation of members of the mitogen-activated protein kinase family by glucose in endothelial cells. Am $J$ Physiol Endocrinol Metab. (2000) 279:E782-90. doi: 10.1152/ajpendo.2000.279.4.E782

102. An J, Huang YC, Xu QZ, Zhou LJ, Shang ZF, Huang B, et al. DNAPKcs plays a dominant role in the regulation of $\mathrm{H} 2 \mathrm{AX}$ phosphorylation in response to DNA damage and cell cycle progression. BMC Mol Biol. (2010) 11:18. doi: 10.1186/1471-2199-11-18

103. Schisano B, Tripathi G, McGee K, McTernan PG, Ceriello A. Glucose oscillations, more than constant high glucose, induce p53 activation and a metabolic memory in human endothelial cells. Diabetologia. (2011) 54:121926. doi: 10.1007/s00125-011-2049-0

104. Liu B, Chen Y, St. Clair DK. ROS and p53: a versatile partnership. Free Radic Biol Med. (2008) 44:1529-35. doi: 10.1016/j.freeradbiomed.2008.01.011

105. Wu Z, Chen Q, Ke D, Li G, Deng W. Emodin protects against diabetic cardiomyopathy by regulating the AKT/GSK-3beta signaling pathway in the rat model. Molecules. (2014) 19:14782-93. doi: 10.3390/molecules190 914782

106. Sun D, Shen M, Li J, Li W, Zhang Y, Zhao L, et al. Cardioprotective effects of tanshinone IIA pretreatment via kinin B2 receptor-Akt-GSK-3beta dependent pathway in experimental diabetic cardiomyopathy. Cardiovasc Diabetol. (2011) 10:4. doi: 10.1186/1475-2840-10-4

107. Miura T, Miki T. GSK-3beta, a therapeutic target for cardiomyocyte protection. Circ J. (2009) 73:1184-92. doi: 10.1253/circj.CJ-09-0284
108. Wang J, Yin H, Huang Y, Guo C, Xia C, Liu Q, et al. Panax quinquefolius saponin of stem and leaf attenuates intermittent high glucose-induced oxidative stress injury in cultured human umbilical vein endothelial cells via PI3K/Akt/GSK-3 beta pathway. Evid Based Compl Alternat Med. (2013) 2013:196283. doi: 10.1155/2013/196283

109. Hajduch E, Balendran A, Batty IH, Litherland GJ, Blair AS, Downes CP, et al. Ceramide impairs the insulin-dependent membrane recruitment of protein kinase B leading to a loss in downstream signalling in L6 skeletal muscle cells. Diabetologia. (2001) 44:173-83. doi: 10.1007/s001250051596

110. Shao C, Gu JQ, Meng X, Zheng HZ, Wang DF. Systematic investigation into the role of intermittent high glucose in pancreatic beta-cells. Int J Clin Exp Med. (2015) 8:5462-9.

111. Biscetti F, Pitocco D, Straface G, Zaccardi F, de Cristofaro R, Rizzo P, et al. Glycaemic variability affects ischaemia-induced angiogenesis in diabetic mice. Clin Sci. (2011) 121:555-64. doi: 10.1042/CS20110043

112. Rose BA, Force T, Wang Y. Mitogen-activated protein kinase signaling in the heart: angels versus demons in a heart-breaking tale. Physiol Rev. (2010) 90:1507-46. doi: 10.1152/physrev.00054.2009

113. Ye X, Cheng X, Liu L, Zhao D, Dang Y. Blood glucose fluctuation affects skin collagen metabolism in the diabetic mouse by inhibiting the mitogenactivated protein kinase and Smad pathways. Clin Exp Dermatol. (2013) 38:530-7. doi: 10.1111/ced.12002

114. Marber MS, Rose B, Wang Y. The p38 mitogen-activated protein kinase pathway-a potential target for intervention in infarction, hypertrophy, and heart failure. J Mol Cell Cardiol. (2011) 51:485-90. doi: 10.1016/j.yjmcc.2010.10.021

115. Yu SH, Yu JM, Yoo HJ, Lee SJ, Kang DH, Cho YJ, et al. Antiproliferative effects of rutin on OLETF rat vascular smooth muscle cells stimulated by glucose variability. Yonsei Med J. (2016) 57:37381. doi: 10.3349/ymj.2016.57.2.373

116. Denise Martin E, De Nicola GF, Marber MS. New therapeutic targets in cardiology: p38 alpha mitogen-activated protein kinase for ischemic heart disease. Circulation. (2012) 126:35768. doi: 10.1161/CIRCULATIONAHA.111.071886

117. Lorenzo O, Picatoste B, Ares-Carrasco S, Ramirez E, Egido J, Tunon J. Potential role of nuclear factor kappaB in diabetic cardiomyopathy. Mediat Inflamm. (2011) 2011:652097. doi: 10.1155/2011/652097

118. Zhang W, Zhao S, Li Y, Peng G, Han P. Acute blood glucose fluctuation induces myocardial apoptosis through oxidative stress and nuclear factor- $\mathrm{kB}$ activation. Cardiology. (2013) 124:11-7. doi: 10.1159/000345436

119. Kizub IV, Pavlova OO, Ivanova IV, Soloviev AI. Protein kinase Cdependent inhibition of $\mathrm{BK}(\mathrm{Ca})$ current in rat aorta smooth muscle cells following gamma-irradiation. Int J Radiat Biol. (2010) 86:2919. doi: $10.3109 / 09553000903564042$

120. Saito S, Thuc LC, Teshima Y, Nakada C, Nishio S, Kondo H, et al Glucose fluctuations aggravate cardiac susceptibility to ischemia/reperfusion injury by modulating MicroRNAs Expression. Circ J. (2016) 80:18695. doi: 10.1253/circj.CJ-14-1218

121. Guo J, Sang Y, Yin T, Wang B, Yang W, Li X, et al. miR-1273g$3 \mathrm{p}$ participates in acute glucose fluctuation-induced autophagy, dysfunction, and proliferation attenuation in human umbilical vein endothelial cells. Am J Physiol Endocrinol Metab. (2016) 310:E734-43. doi: 10.1152/ajpendo.00444.2015

122. Weng J, Li Y, Xu W, Shi L, Zhang Q, Zhu D, et al. Effect of intensive insulin therapy on beta-cell function and glycaemic control in patients with newly diagnosed type 2 diabetes: a multicentre randomised parallelgroup trial. Lancet. (2008) 371:1753-60. doi: 10.1016/S0140-6736(08)6 0762-X

123. Pennartz C, Schenker N, Menge BA, Schmidt WE, Nauck MA, Meier JJ. Chronic reduction of fasting glycemia with insulin glargine improves firstand second-phase insulin secretion in patients with type 2 diabetes. Diabetes Care. (2011) 34:2048-53. doi: 10.2337/dc11-0471

124. Bruttomesso D, Crazzolara D, Maran A, Costa S, Dal Pos M, Girelli A, et al. In type 1 diabetic patients with good glycaemic control, blood glucose variability is lower during continuous subcutaneous insulin infusion than during multiple daily injections with insulin glargine. Diabet Med. (2008) 25:326-32. doi: 10.1111/j.1464-5491.2007.0 2365.x 
125. Bailey TS, Pettus J, Roussel R, Schmider W, Maroccia M, Nassr N, et al. Morning administration of $0.4 \mathrm{U} / \mathrm{kg} /$ day insulin glargine $300 \mathrm{U} / \mathrm{mL}$ provides less fluctuating 24-hour pharmacodynamics and more even pharmacokinetic profiles compared with insulin degludec $100 \mathrm{U} / \mathrm{mL}$ in type 1 diabetes. Diabetes Metab. (2018) 44:15-21. doi: 10.1016/j.diabet.2017.10.001

126. Mori K, Emoto M, Abe M, Inaba M. Visualization of blood glucose fluctuations using continuous glucose monitoring in patients undergoing hemodialysis. J Diabetes Sci Technol. (2019) 13:413-4. doi: 10.1177/1932296818818429

127. Klonoff DC, Ahn D, Drincic A. Continuous glucose monitoring: a review of the technology and clinical use. Diabetes Res Clin Pract. (2017) 133:17892. doi: 10.1016/j.diabres.2017.08.005

128. Mian Z, Hermayer KL, Jenkins A. Continuous glucose monitoring: review of an innovation in diabetes management. Am J Med Sci. (2019) doi: 10.1016/j.amjms.2019.07.003. [Epub ahead of print].

129. Yoo HJ, An HG, Park SY, Ryu OH, Kim HY, Seo JA, et al. Use of a real time continuous glucose monitoring system as a motivational device for poorly controlled type 2 diabetes. Diabetes Res Clin Pract. (2008) 82:739. doi: 10.1016/j.diabres.2008.06.015

130. Juvenile Diabetes Research Foundation Continuous Glucose Monitoring Study Group, Tamborlane WV, Beck RW, Bode BW, Buckingham B, Chase
HP, et al. Continuous glucose monitoring and intensive treatment of type 1 diabetes. N Engl J Med. (2008) 359:1464-76. doi: 10.1056/NEJMoa0805017

131. Renard E, Schaepelynck-Belicar P, Group E. Implantable insulin pumps. A position statement about their clinical use. Diabetes Metab. (2007) 33:15866. doi: 10.1016/j.diabet.2006.10.004

132. Raccah D, Sulmont V, Reznik Y, Guerci B, Renard E, Hanaire H, et al. Incremental value of continuous glucose monitoring when starting pump therapy in patients with poorly controlled type 1 diabetes: the RealTrend study. Diabetes Care. (2009) 32:2245-50. doi: 10.2337/dc09-0750

Conflict of Interest Statement: The authors declare that the research was conducted in the absence of any commercial or financial relationships that could be construed as a potential conflict of interest.

Copyright (๑ 2019 Zhang, Miao, Qian, Wang, Qi, Zhang, Dang, Wu and Wang. This is an open-access article distributed under the terms of the Creative Commons Attribution License (CC BY). The use, distribution or reproduction in other forums is permitted, provided the original author(s) and the copyright owner(s) are credited and that the original publication in this journal is cited, in accordance with accepted academic practice. No use, distribution or reproduction is permitted which does not comply with these terms. 